\title{
CÓMO MEJORAR EL RAZONAMIENTO CAUSAL Y LA MOTIVACIÓN CIENTÍFICA EN LA EDUCACIÓN INTELECTUAL DE LOS ESTUDIANTES DE MEDICINA. UTILIZACIÓN DE NUEVAS TECNOLOGÍAS EN LA METODOLOGÍA DOCENTE.
}

\section{Resumen:}

La utilización de nuevas tecnologías en metodología docente no constituye una finalidad en sí misma sino un instrumento al servicio de un objetivo educativo. Partiendo de las ideas formuladas por Abraham Flexner hace 100 años, nuestro objetivo educativo consiste en mejorar el razonamiento científico de los estudiantes de Medicina. Para conseguirlo, reducimos la cantidad de información suministrada a los estudiantes y ponemos el énfasis en las relaciones causales entre las variables responsables de las principales funciones fisiológicas. Por otra parte, tratamos de transmitir a los estudiantes la emoción de los descubrimientos científicos y les damos la oportunidad de trabajar durante un tiempo en la poyata de un laboratorio. La utilización de las nuevas tecnologías de la comunicación permite tutelar, de manera individualizada, la formación intelectual de nuestros estudiantes, haciendo accesible a un gran número de ellos lo que en otro tiempo fue el privilegio de un número reducido de discípulos.

Palabras clave: Educación científica, tablet PC-OneNote, programas multimedia, Internet, Moodle, podcasts, pósters, presentaciones multimedia, poyata de laboratorio.

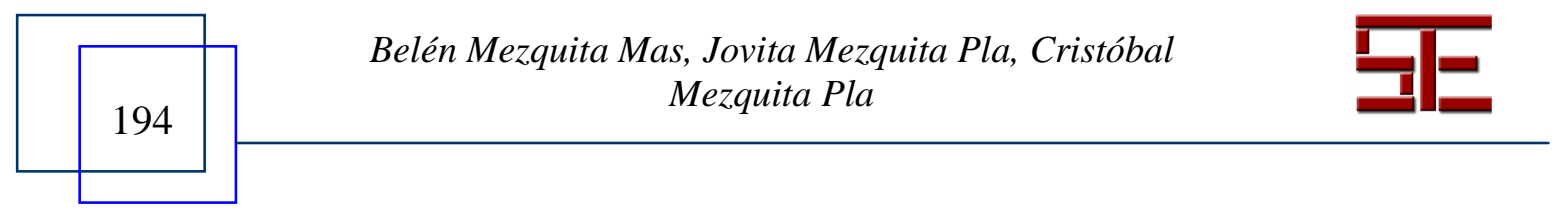




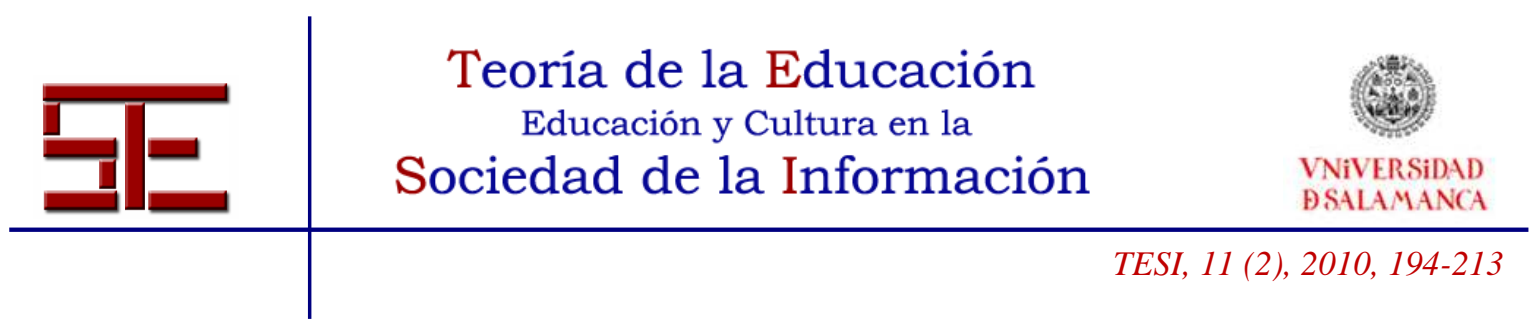

\title{
HOW TO IMPROVE THE CAUSAL REASONING AND SCIENTIFIC MOTIVATION IN THE INTELLECTUAL TRAINING OF MEDICAL STUDENTS. USE OF NEW LEARNING TECHNOLOGIES.
}

\begin{abstract}
:
New learning technologies are not an end in their own right, but an instrument to achieve a learning objective. Based on the ideas formulated by Abraham Flexner a century ago, our main educational objective consists of improving the scientific reasoning of medical students. To achieve this goal we reduce the amount of information given to students and put the emphasis on the causal relationships between those variables that are the foundation of physiological functions. In addition, we try to bring to students the excitement of the scientific discoveries and to give them the opportunity to work for a period of time at a lab bench. New learning technologies allow tutoring students individually, extending to a considerable number of students the education that in past times was the privilege of very few disciples.
\end{abstract}

Key words:Scientific education, tablet PC-OneNote, multimedia programs, Internet, Moodle, podcasts, posters, multimedia presentations, lab bench.

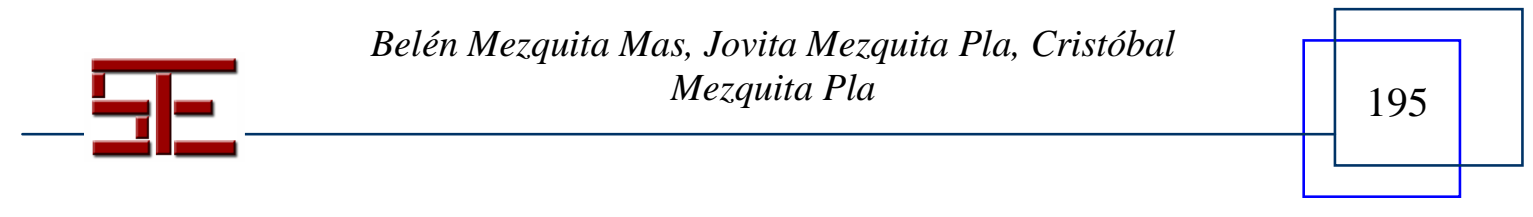


CÓMO MEJORAR EL RAZONAMIENTO CAUSAL Y LA MOTIVACIÓN CIENTÍFICA EN LA EDUCACIÓN INTELECTUAL DE LOS ESTUDIANTES DE MEDICINA. UTILIZACIÓN DE NUEVAS TECNOLOGÍAS EN LA METODOLOGÍA DOCENTE.

Fecha de recepción: 15/12/2009; fecha de aceptación: 07/05/2010; fecha de publicación: 051/07/2010

Belén Mezquita Mas

belenmezquita@ub.edu

Universidad de Barcelona

Jovita Mezquita Pla

jmezquita@ub.edu

Universidad de Barcelona

Cristóbal Mezquita Pla

cmezquita@ub.es

Universidad de Salamanca

\section{1.- INTRODUCCIÓN}

Un artículo de la prensa diaria que comentaba la utilización por parte de nuestro equipo docente de avances tecnológicos en metodología educativa tenía el provocativo y equivocado encabezamiento de "Muerte a la pizarra". La pizarra, convencional o electrónica, es un instrumento insustituible de comunicación en tiempo real, que ha jugado un papel educativo esencial en los dos últimos siglos. En los pasillos de una de las empresas más grandes de informática, la estadounidense Microsoft Corporation, con sede en Redmond, Washington, cada pocos metros hay una pizarra, y en torno a ella, un grupo de personas intercambiando ideas. La comunicación "online" aún no ha reemplazado por completo el diálogo en torno a una pizarra.

Sirva esta anécdota de la pizarra para destacar, desde el principio, que en metodología docente es fundamental una actitud ecléctica: no todo lo nuevo es bueno ni todo lo

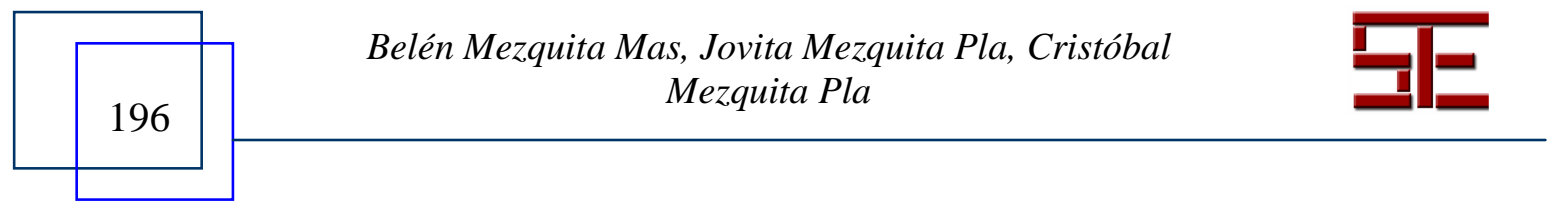




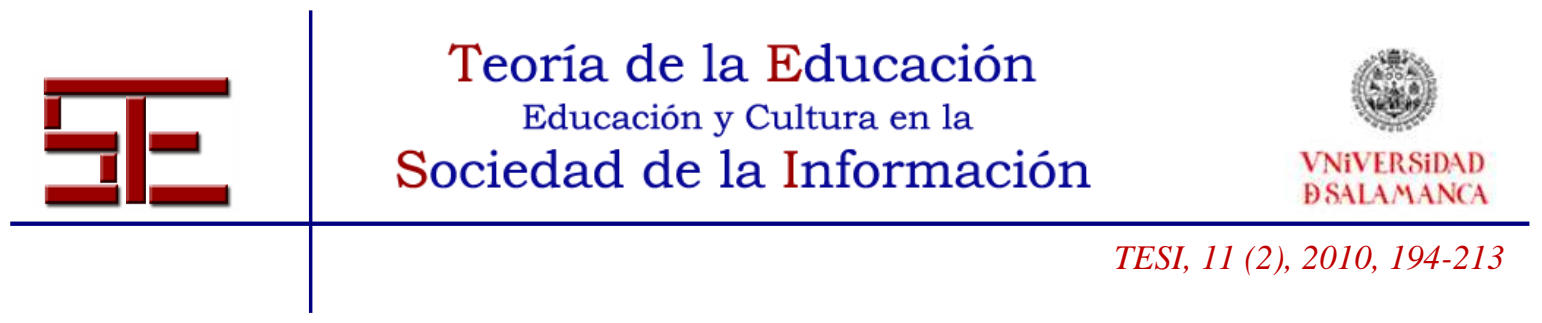

bueno es nuevo. Por otra parte, la tecnología utilizada en docencia no tiene valor en sí misma y carece de utilidad si no está al servicio de una idea. Por este motivo expondremos, en primer lugar, cuál es nuestra idea directriz en la docencia universitaria, y a continuación, cómo utilizamos las nuevas tecnologías al servicio de esa idea.

\section{2.- EDUCAR EN EL RAZONAMIENTO CIENTÍFICO}

Hace 100 años Abraham Flexner, después de investigar la enseñanza de la Medicina en 155 Facultades de Medicina de los Estados Unidos y Canadá, llegó a la conclusión de que la educación científica en las Facultades de Medicina europeas, por ejemplo en las alemanas, era muy superior a la educación científica adquirida en la mayoría de las Facultades de Medicina de Norte América. Algunas facultades, como la Johns Hopkins, constituían la excepción y el ideal. Postulaba Flexner que era esencial educar a los estudiantes de Medicina en el razonamiento científico (Cooke et al., 2006).

En el libro "To err is human" (Kohn et al., 1999) se evalúan los errores médicos como la octava causa de muerte en los Estados Unidos, por delante de los accidentes de tráfico. Los errores de razonamiento contribuyen mayormente a los errores médicos. Los errores de razonamiento son la consecuencia de una educación médica deficiente (Patel et al., 2004). Por estos motivos, nuestro principal objetivo consiste en desarrollar y fortalecer el razonamiento causal (Mezquita et al., 2009).

La actividad científica tiene actualmente una posición dominante en muchas Facultades de Medicina y a ella se supeditan la actividad docente y la actividad asistencial. Se dedican a la investigación la mayor parte del tiempo y de los recursos y constituye prácticamente la única base de selección y promoción del profesorado. No era esta la idea de Flexner. Según él, la actividad científica de las Facultades de Medicina no debía constituir una finalidad en sí misma y debía supeditarse a la educación de los estudiantes y a la atención de los enfermos. En la actualidad se da la paradoja de que, aunque, en apariencia, tenemos mucha ciencia en las Facultades de Medicina, la implicación de la ciencia en la educación médica sigue siendo escasa. Incluso, algunas consecuencias del desarrollo científico pueden resultar negativas para la educación, por ejemplo, el exceso de información, la atomización del conocimiento y la falta de dedicación a la docencia.

\section{3.- ASIGNATURA “FISIOLOGÍA MÉDICA".}

Una de las asignaturas que impartimos a los estudiantes de segundo curso de medicina trata de la fisiología de los sistemas circulatorio, respiratorio y renal. Para la docencia de esta asignatura utilizamos diferentes instrumentos que describimos a continuación: libro

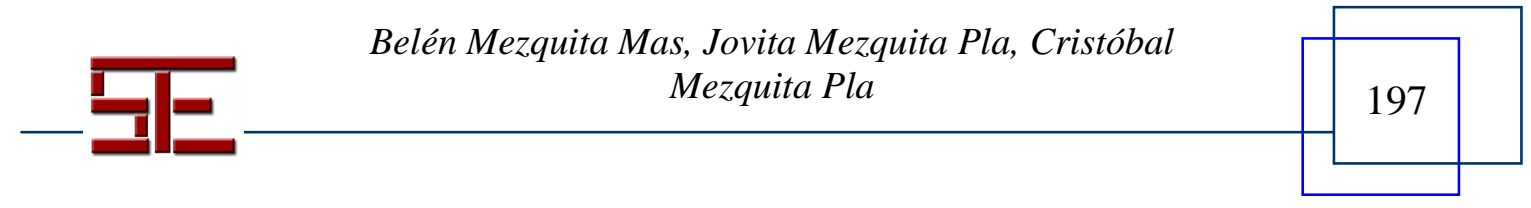




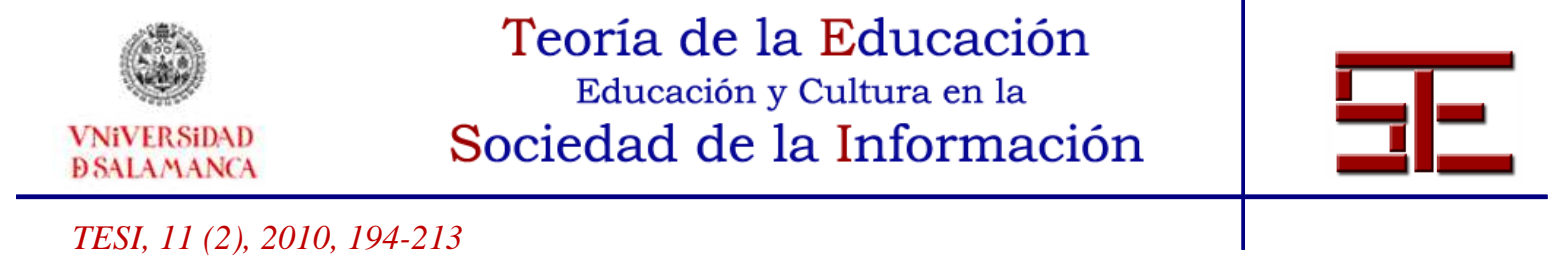

de texto, web de la asignatura, plataforma Moodle, clases teóricas, clases prácticas, comunicaciones orales y pósters de los estudiantes y evaluación continuada.

\section{1.- Libro de texto.}

La elaboración de un libro de texto permite limitar las explicaciones de las clases teóricas a determinados temas y dejar que el alumno estudie el resto en el libro. El texto proporciona la información necesaria para definir un conjunto de variables fisiológicas de cada sistema, establecer los rangos normales de variación y las relaciones entre variables independientes y variables función, mediante fórmulas, gráficas o, en su defecto, de forma cualitativa (Mezquita y Mezquita, 2010; Mezquita, 2010). El libro de texto pone un especial énfasis en diferenciar los factores determinantes directos de una variable, es decir, las causas inmediatas de un fenómeno, de otras causas que operan de forma remota. Cada lección propone un conjunto de "tareas de razonamiento" para ser realizadas por los estudiantes. Las tareas consisten en construir una concatenación causal, un diagrama causa-efecto a partir de un conjunto de variables. Para iniciar la concatenación, en unos casos se plantea las causas de la desviación de una variable, en otros sus consecuencias o bien, las causas y consecuencias. A continuación se muestran dos ejemplos, de un total de 112 tareas planteadas en el libro de texto.

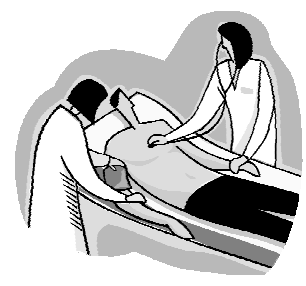

\section{Consecuencias de una hemorragia gastrointestinal.}

A partir de las variables que se indican a continuación, establece una concatenación causal que explique las consecuencias de una hemorragia gastrointestinal.

SANGRE:

- Hematocrito, disminuido.

SISTEMA CIRCULATORIO:

- Presión arterial, disminuida.

- Taquicardia.

- Vasoconstricción.

- Volemia, disminuida.

- Volumen sistólico, disminuido.

- Volumen minuto, disminuido.

- Flujo sanguíneo a los tejidos, disminuido.

- Actividad de los barorreceptores, disminuida.

SISTEMA ENDOCRINO:

- Angiotensina II, elevada.

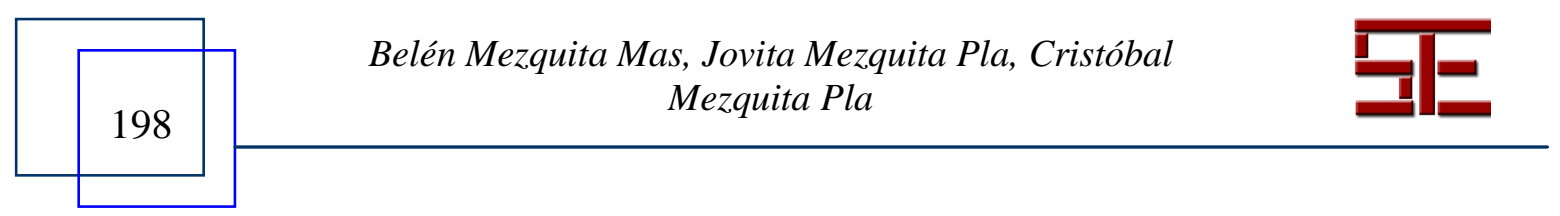




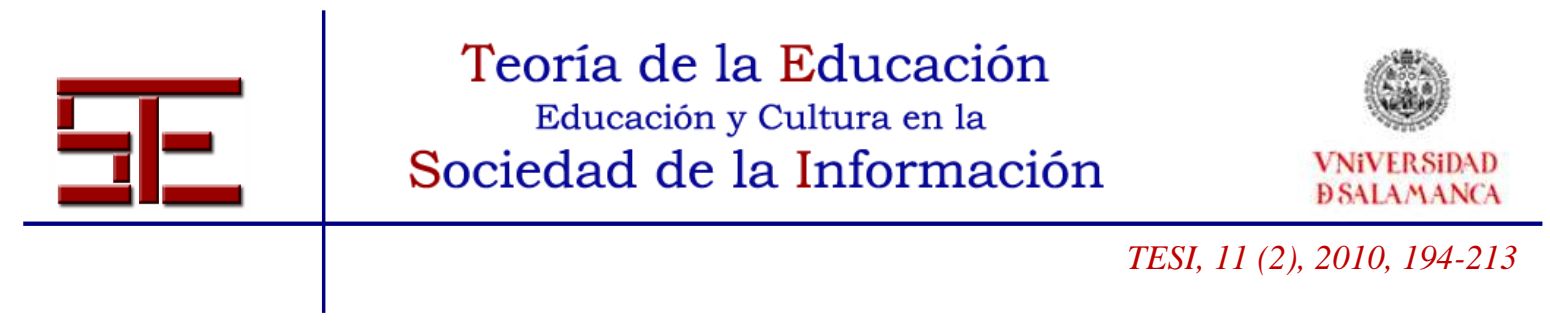

- Aldosterona, elevada.

SISTEMA RENAL:

- Retención de $\mathrm{Na}+$

- Aumento del volumen del líquido extracelular.

- Renina elevada

SISTEMA CUTÁNEO:

- Piel pálida y fría.

ALTERACIONES PATOLÓGICAS:

- Hemorragia gastrointestinal.

SISTEMA NERVIOSO VEGETATIVO:

- Activación del simpático.

- Disminución del tono vagal cardíaco

Antes de establecer la concatenación causal, verifica que sabes definir las variables implicadas y que conoces, si es pertinente, sus valores fisiológicos. Después de establecer la concatenación, verifica que sabes razonar las relaciones causales señaladas por las flechas.
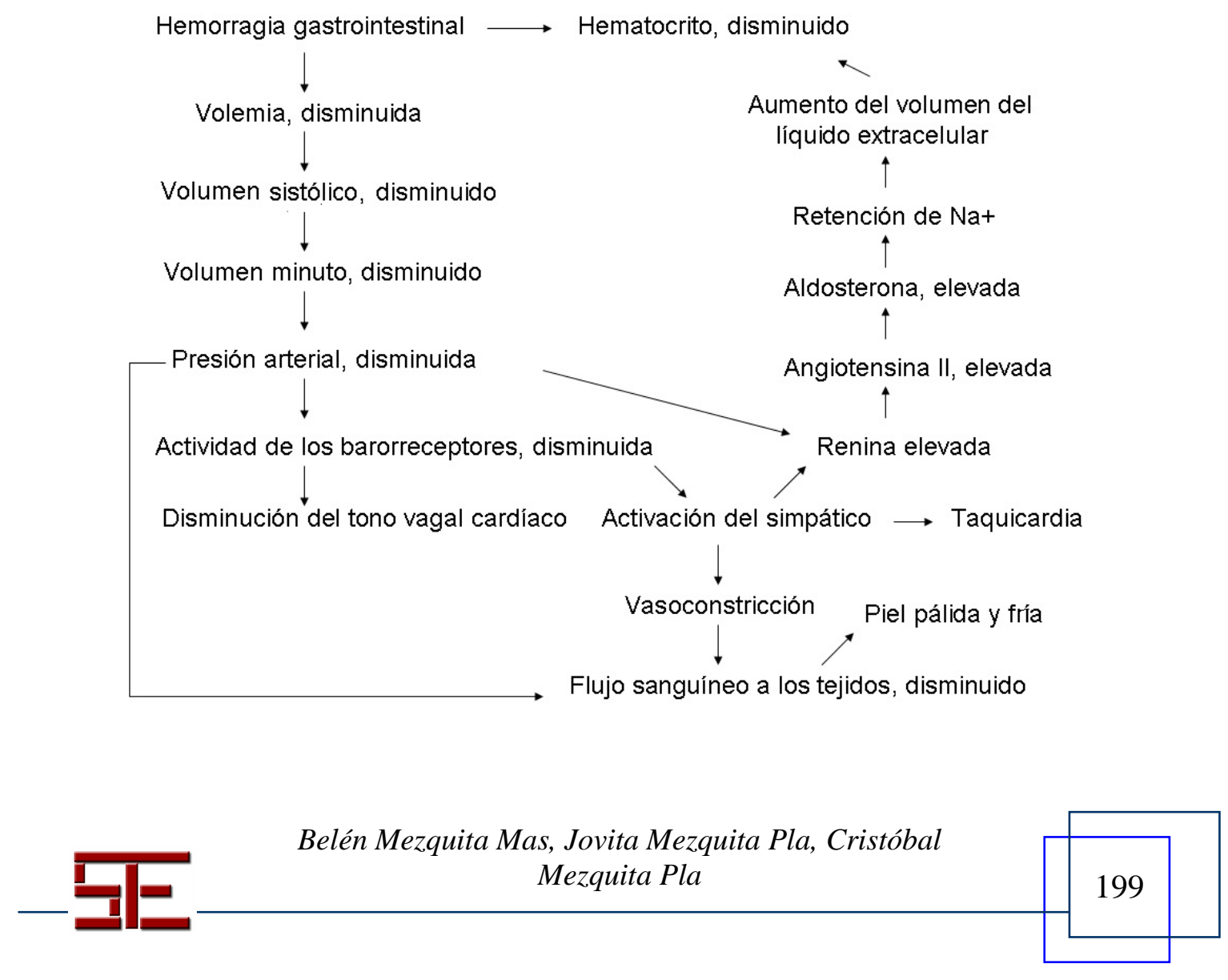

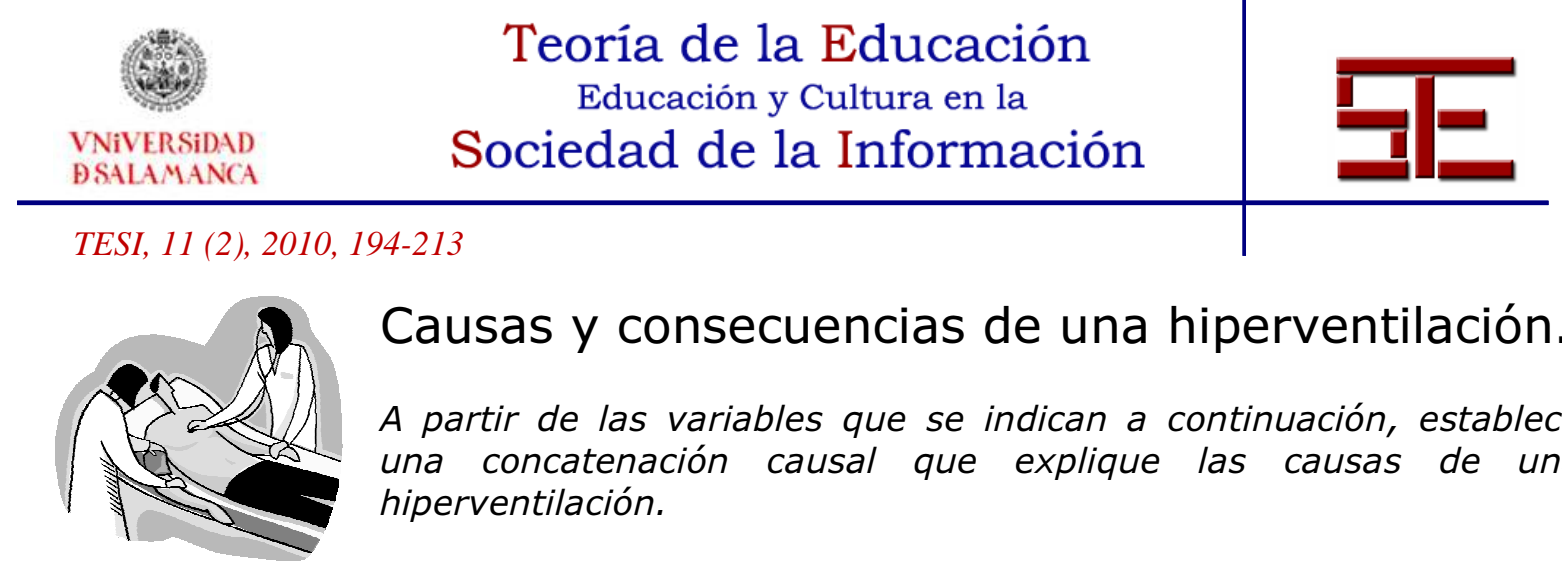

Causas y consecuencias de una hiperventilación.

A partir de las variables que se indican a continuación, establece una concatenación causal que explique las causas de una hiperventilación.

- $\mathrm{pAO}_{2}$, disminuida.

- $\mathrm{pACO}_{2}$, disminuida.

- $\mathrm{paO}_{2}$, disminuida.

- $\mathrm{paCO}_{2}$, disminuida.

- Hiperventilación.

- Activación de los quimiorreceptores periféricos.

- Saturación de la hemoglobina, disminuida.

- Producción renal de eritropoyetina, augmentada.

- Disminución de la presión barométrica.

- Concentración de hemoglobina, aumentada.

- Policitemia.

- Viscosidad de la sangre, aumentada.

- Resistencias circulatorias, aumentadas.

- Alcalemia.

- Contenido arterial de 02, disminuido.

Antes de establecer la concatenación causal, verifica que sabes definir las variables implicadas y que conoces, si es pertinente, sus valores fisiológicos. Después de establecer la concatenación, verifica que sabes razonar las relaciones causales señaladas por las flechas.

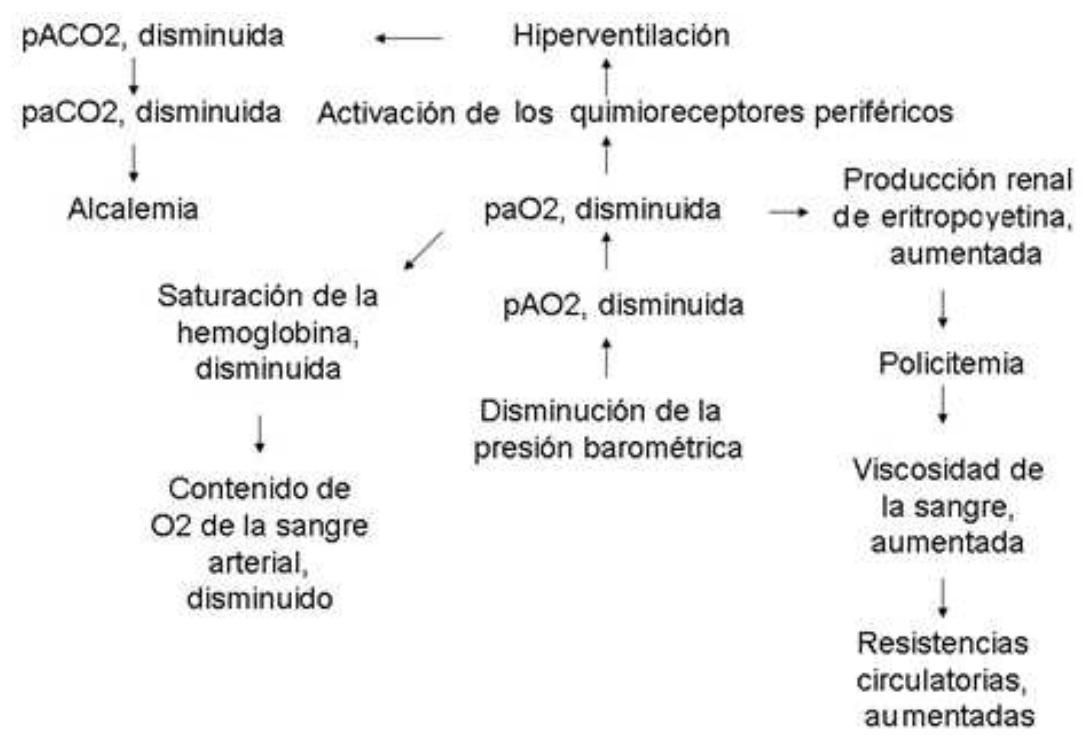

Belén Mezquita Mas, Jovita Mezquita Pla, Cristóbal Mezquita Pla 


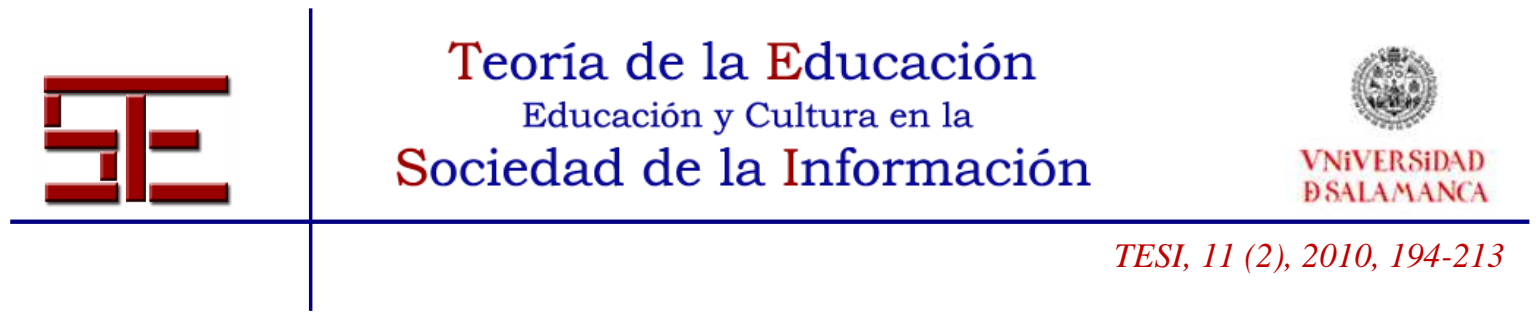

El libro de texto contiene un CD con el conjunto de ilustraciones gráficas y animaciones de las diferentes lecciones. Los alumnos pueden escribir, editar y grabar pies explicativos de las ilustraciones. Esta tarea sirve de preparación para las intervenciones en clase, cuando los estudiantes son requeridos por el profesor para comentar algunas ilustraciones. El CD da acceso a la web de la asignatura y al sistema de gestión de cursos Moodle.

\section{2.- Web de la asignatura.}

La página principal de la web www.fisiologia.net da acceso a las páginas de las asignaturas impartidas por nuestro equipo docente: fisiología de los sistemas circulatorio, respiratorio y renal, fisiología de la reproducción y el desarrollo, "biomedical discoveries" y biología molecular del cáncer. Además, permite acceder a la página web de nuestro laboratorio (Fig. 1).

Comentaremos aquí únicamente el contenido de la página relativo a la asignatura "fisiología de los sistemas circulatorio, respiratorio y renal" a la que se puede acceder a través de la dirección indicada anteriormente. Las secciones de la página web de esta asignatura son las siguientes: guía de la asignatura, profesores, agenda, seminarios científicos de facultad, calendario, libro de texto, prácticas, tareas, presentaciones orales y pósters, acceso a moodle, acceso a búsquedas bibliográficas, actualizaciones (UpToDate), diccionarios, clases on-line y enlaces de fisiología (Fig. 2).

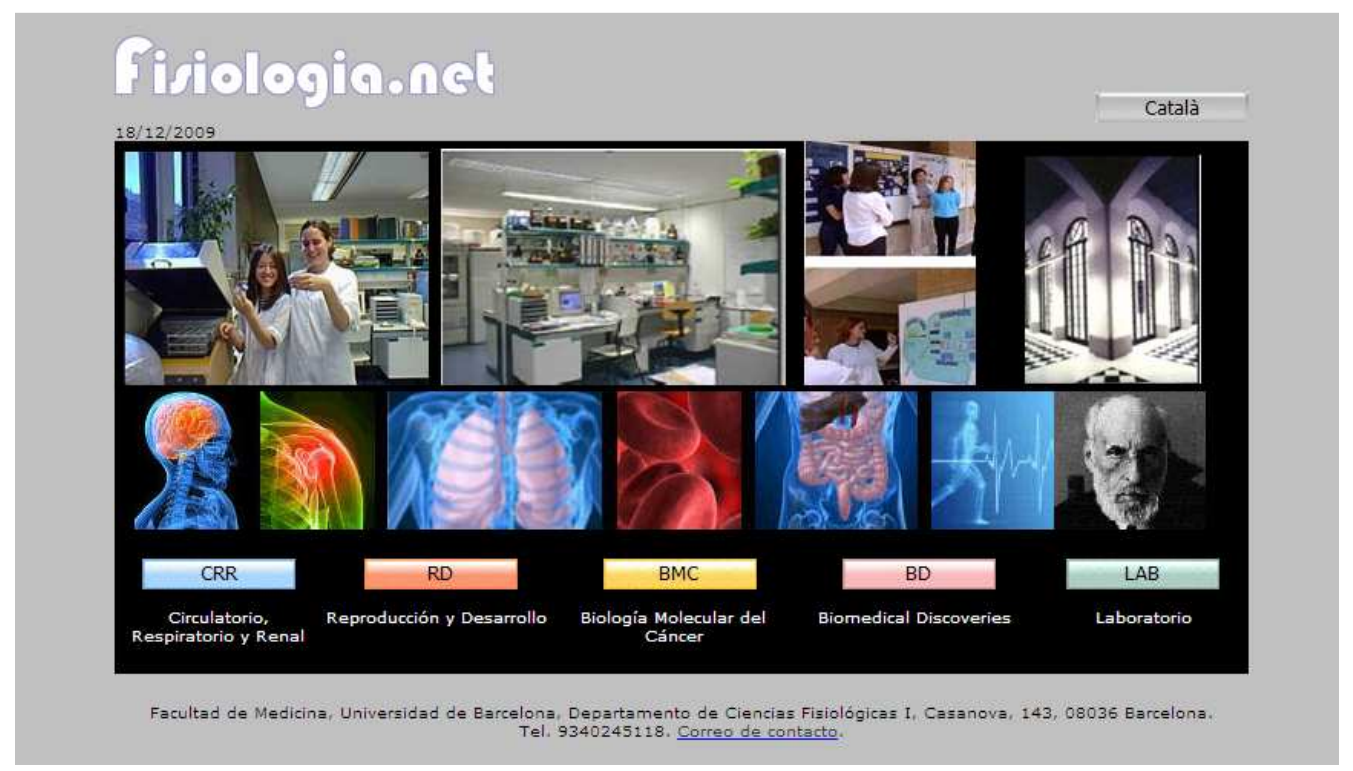

Fig. 1. Web de las asignaturas impartidas por nuestro equipo docente.

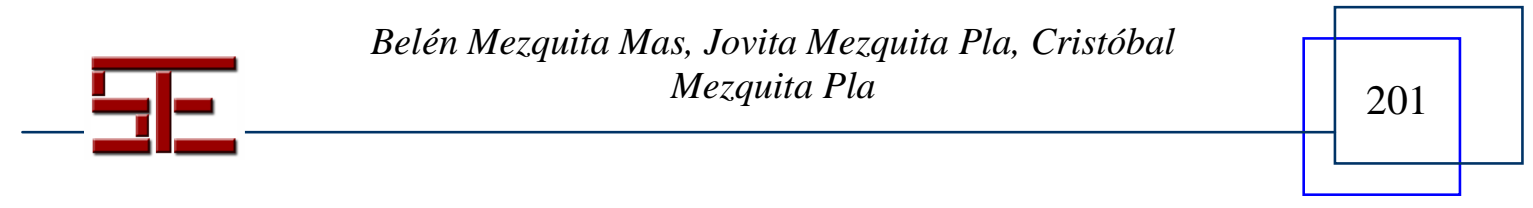




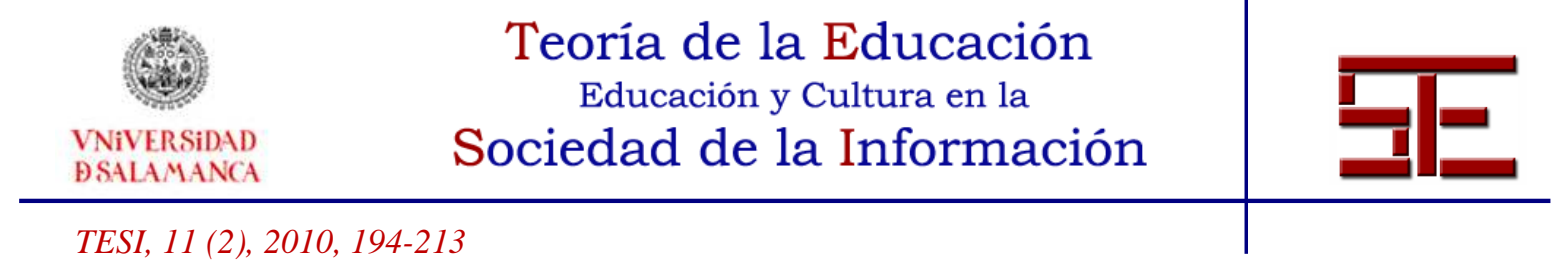

\section{3.- Sistema de gestión de cursos Moodle.}

A este sistema de gestión se accede a través del campus virtual de la Universidad de Barcelona (Figura 3). El contenido de la página es el siguiente: enlaces con la página web de la asignatura, noticias, dudas, trabajos bibliográficos, protocolos prácticas, autoevaluaciones, errores, contradicciones y discrepancias en las explicaciones de los profesores y en los libros de texto. La principal ventaja del sistema de gestión Moodle es la facilidad con la que se puede contactar con cada estudiante y gestionar el curso.

\section{4.- Clases teóricas}

El escenario físico de las clases teóricas es idealmente el de un aula que facilite el diálogo con los estudiantes, equipada con un proyector con luminosidad suficiente para mantener una adecuada luz ambiental. El proyector se conecta a un ordenador portátil tablet-PC que opera con el programa OneNote de Microsoft Office que resulta ideal como pizarra electrónica.

La utilización de los programas multimedia en las clases teóricas se ha generalizado. Uno de los peores inconvenientes de estos programas es la avalancha de información prefabricada que pueden proyectar, a veces vertida a una velocidad tal que impide cualquier posibilidad de razonamiento por parte de los estudiantes que asisten, resignados, sumidos en el denominado "efecto cine", esperando que ulteriormente se les suministre la información de las diapositivas en el servicio de fotocopias o en Internet.

A pesar de los posibles abusos, la utilización de imágenes estáticas, vídeos y animaciones es de gran utilidad para ilustrar conceptos, siempre que se alterne con la utilización de la pizarra en tiempo real. Para conseguir una transición suave entre la pizarra y los programas multimedia, resulta ideal la utilización del tablet-PC con el programa OneNote como pizarra electrónica. De esta manera, el profesor puede escribir y dibujar sobre la pantalla del ordenador y proyectar lo que escribe o dibuja en la pantalla. Todo el contenido de la clase puede grabarse en formato HTML y depositarse en Internet para ser consultado ulteriormente por los estudiantes.

Para las presentaciones multimedia utilizamos el programa Authorware de Macromedia (Adobe). Debido a que Adobe ha decidido no renovar este programa, en la actualidad utilizamos también como alternativa el programa PowerPoint de Microsoft Office con el complemento de otro programa, el Articulate Presenter. La ventaja de este programa es que permite la publicación en formato "flash", lo que facilita la utilización en Internet. El programa permite crear e incluir autoevaluaciones.

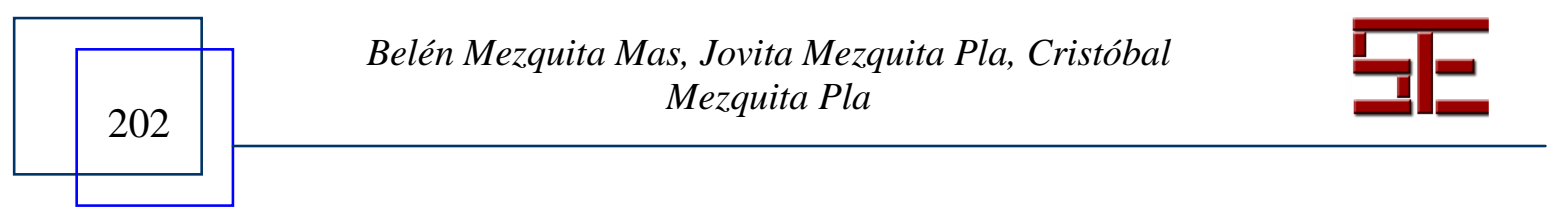



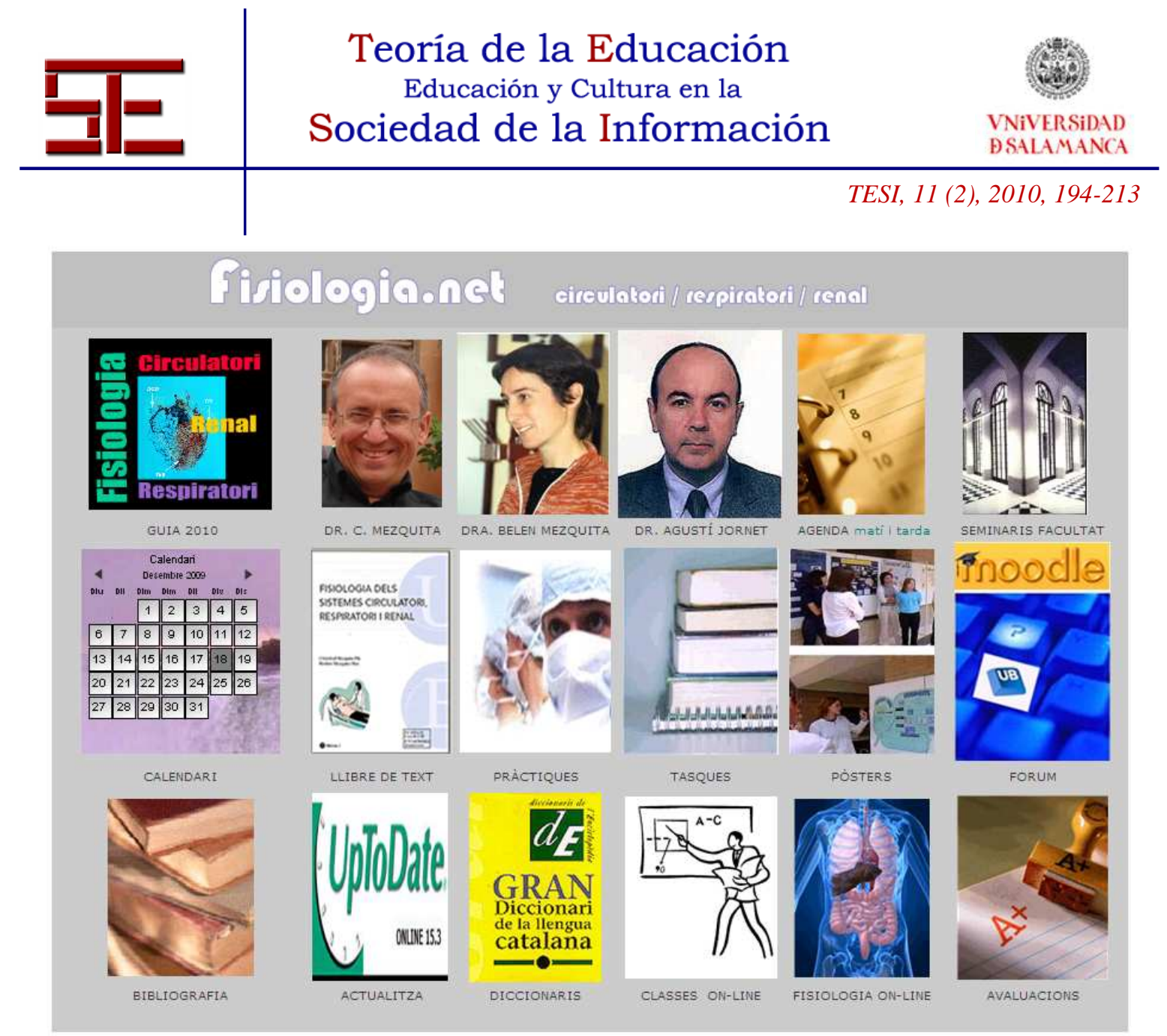

Fig. 2. Página web de la asignatura "Fisiología de los Sistemas Circulatorio, Respiratorio y Renal"

Así pues, en clase alternamos la utilización en directo de la pizarra electrónica (tablet PC-OneNote) con el programa multimedia Authorware o PowerPoint-Articulate Presenter. Una posibilidad intermedia consiste en grabar algunos contenidos en tiempo real de la pizarra y mostrarlos, de manera que la audiencia no puede distinguir fácilmente si lo que se proyecta se está transmitiendo en directo o de forma diferida. Para generar estos vídeos, capturamos los contenidos de la pizarra con el programa Microsoft Expression Encoder 3. El formato de grabación en MP4, permite mostrar los vídeos en el programa PowerPoint-Articulate Presenter.

La monotonía de la proyección de diapositivas puede romperse no sólo mediante la alternancia con la utilización de la pizarra sino, además, siempre que resulte factible, con la proyección de variables fisiológicas del profesor, por ejemplo la actividad eléctrica del corazón, en tiempo real. El profesor conecta los cables de los electrodos al ordenador portátil y comenta en pantalla su electrocardiograma.

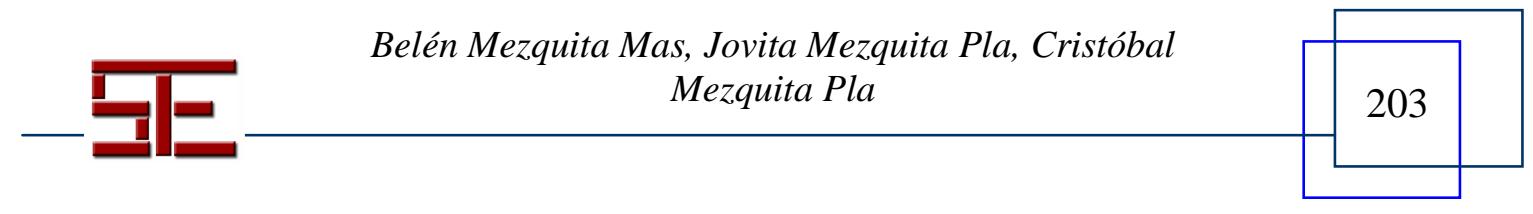



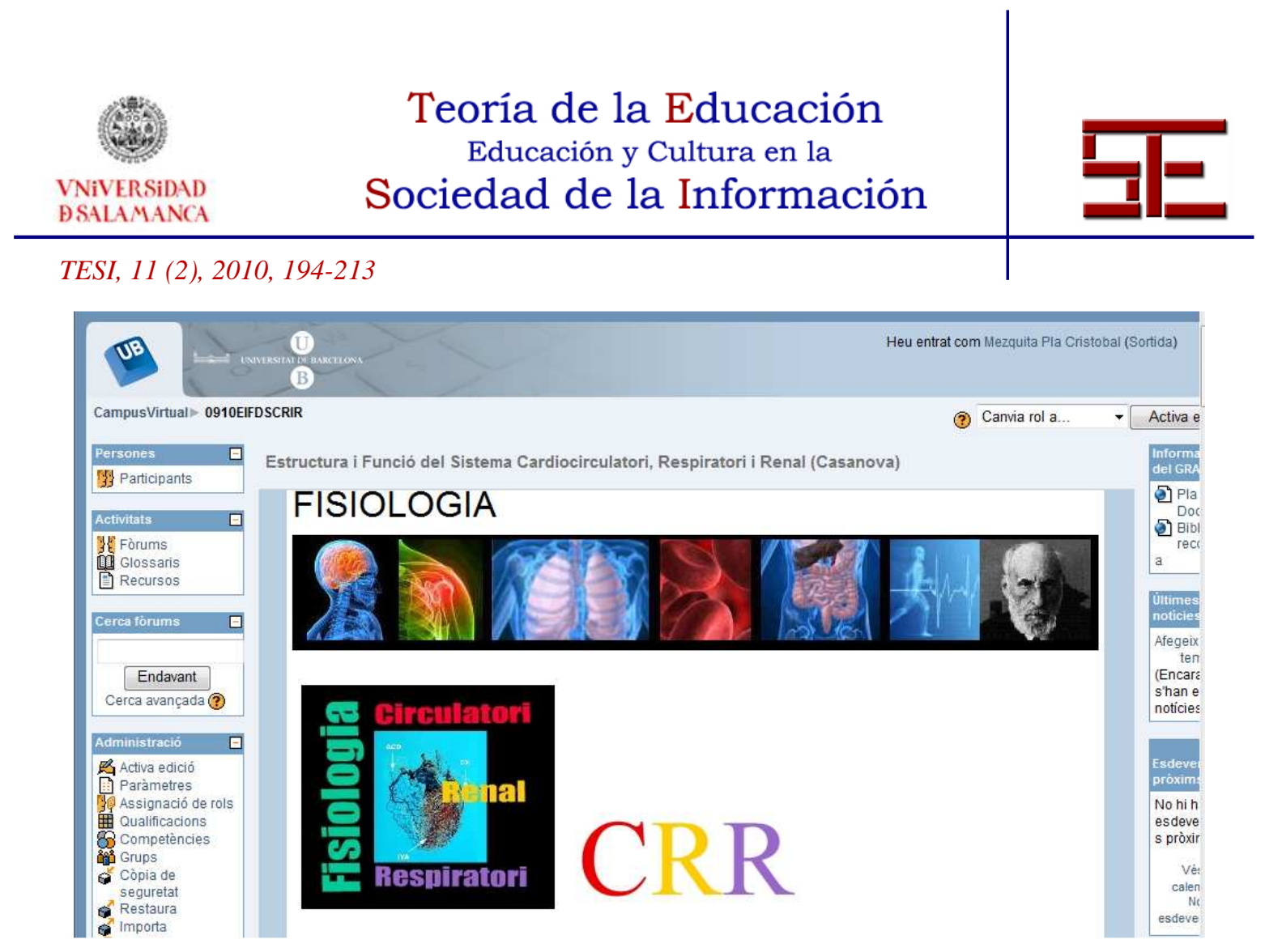

Fig. 3. La plataforma Moodle facilita la comunicación individualizada con los estudiantes y la gestión de datos.

En todo caso, el elemento más importante, absolutamente imprescindible en las clases teóricas no son las nuevas tecnologías sino la interacción profesor-alumno, el diálogo. En principio parece que el diálogo sea difícil o imposible, en una clase de un centenar de alumnos, pero no es así. Los estudiantes deben estar mentalizados que van a clase para participar activamente y no únicamente como espectadores pasivos. Un requisito para ir a clase es que los estudiantes hayan previamente estudiado en el libro de texto los temas a discutir y hayan realizado las tareas programadas. El profesor, durante la clase, requiere la intervención de los alumnos en cualquier momento. Para ello, un programa de ordenador selecciona aleatoriamente a un estudiante y proyecta su nombre en pantalla. Al final de la clase, el profesor dispone de un fichero en el que quedan registrados todos los estudiantes que han intervenido. En el programa OneNote queda constancia de la intervención de los estudiantes para su evaluación ulterior.

Algunas de las tareas planteadas implican búsquedas bibliográficas por parte de los estudiantes. Los estudiantes que han realizado las tareas bibliográficas pueden ser requeridos por el profesor para comentarlas en la clase que, por el tema tratado, resulte pertinente. Tal como se ha comentado anteriormente, otra actividad de los estudiantes, en clase, puede ser el comentario de una ilustración gráfica. La participación de los estudiantes en la clase teórica es objeto de evaluación. Se evalúa positivamente la

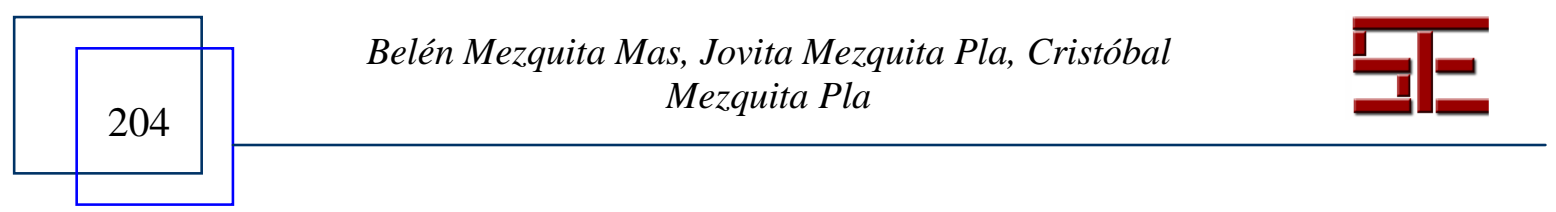




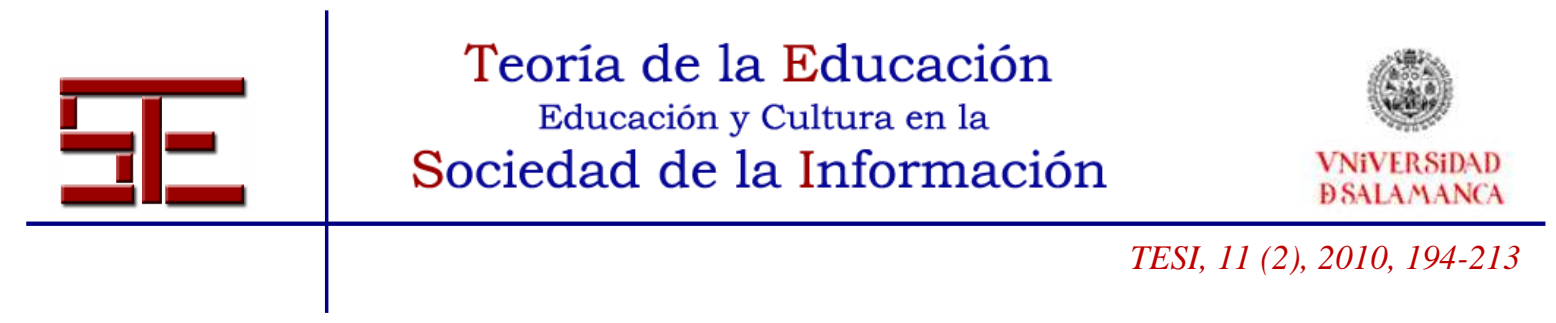

asistencia a clase y el estar al día. A través de estas actividades en clase, los estudiantes adquieren el hábito de la comunicación oral frente a una audiencia numerosa.

El contenido de las clases, lo que se escribe en la pizarra y las presentaciones multimedia, se deposita en Internet para ser utilizado ulteriormente por los estudiantes. Esta facilidad podría disuadir a algunos estudiantes de la asistencia a clase pero no se produce absentismo, puesto que la participación activa en clase es objeto de evaluación.

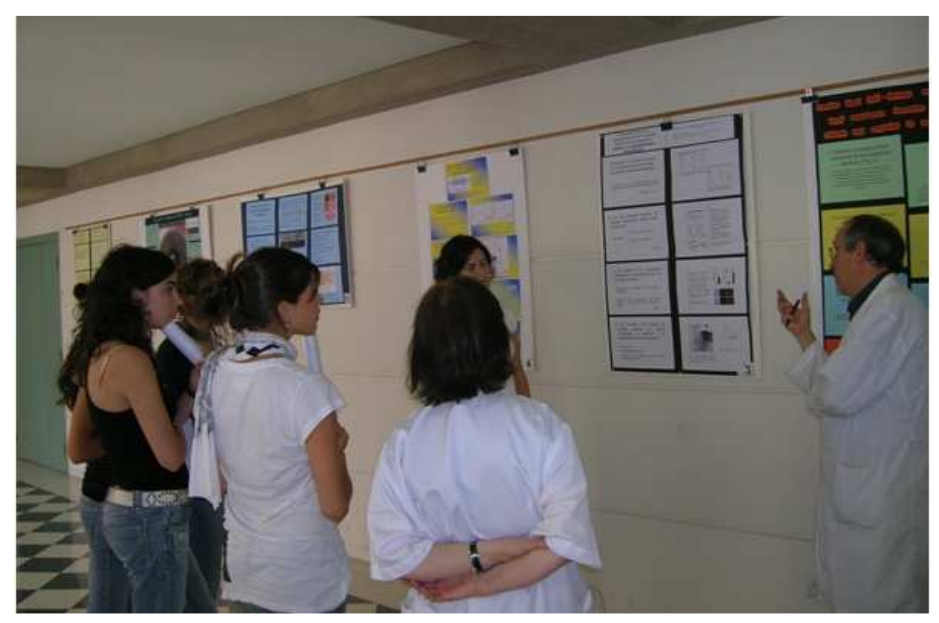

Fig. 4. La preparación de pósters y presentaciones orales multimedia se utiliza para practicar la comunicación científica.

\section{5.- Clases prácticas}

Realizamos diferentes tipos de clases prácticas: las clases prácticas para resolución de las tareas de razonamiento planteadas, las clases prácticas de exploración funcional en los laboratorios de fisiología, en laboratorios virtuales o en medio hospitalario.

\section{Clases prácticas para la resolución tutelada de tareas programadas}

El escenario físico de estas clases prácticas es el siguiente: cinco mesas para cuatro personas cada una. Cada mesa dispone de una pequeña pizarra. La duración de la clase es de dos horas. En cada mesa, el grupo de cuatro personas encuentra una carpeta que contiene las tareas a realizar. Estas tareas consisten en diagramas causa-efecto en los cuales los estudiantes deben ordenar un conjunto de variables para determinar las causas de un fenómeno o las consecuencias de la desviación de una variable, tal como se ha indicado anteriormente. Durante una hora, el grupo elabora los diagramas y responde a

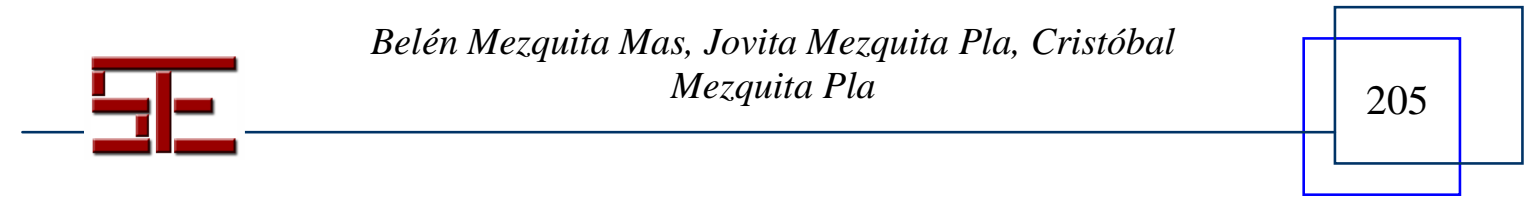




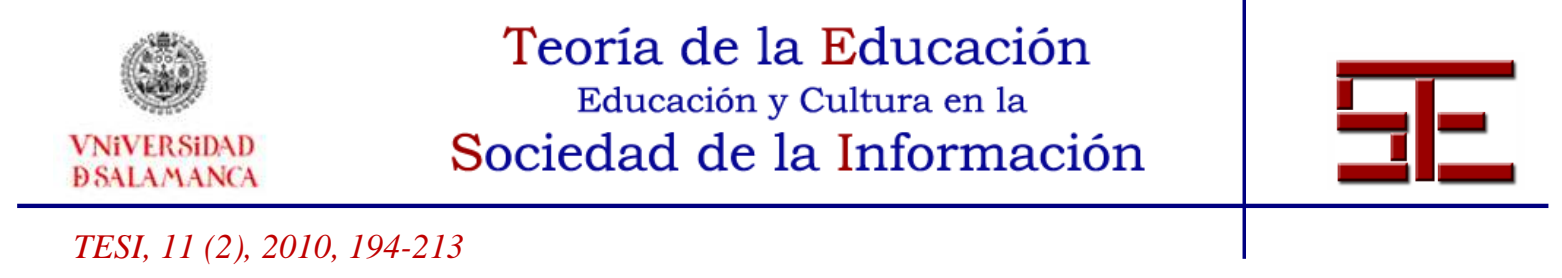

las preguntas formuladas. Al cabo de este tiempo el profesor recoge los resultados y, durante 10 minutos, formula preguntas individualmente y de forma aleatoria a los integrantes del grupo. De esta forma, estas prácticas son objeto de evaluación continuada. En lugar de las tareas descritas, la carpeta puede contener un número reducido de cuestiones a contestar de forma individual, y que son objeto de evaluación. Los tests tienen cuestiones de los tipos siguientes: definiciones, afirmaciones verdadero/falso, relaciones entre variables (respuestas múltiples), gráficas (dibujo y/o rotulación). Si los estudiantes disponen de ordenadores portátiles, el cuestionario lo pueden responder por vía telemática. Para elaborar los test telemáticos preparamos los cuestionarios con los programas Authorware (Adobe), Wondershare Quiz Creator o Articulate Quiz Maker.

Clases prácticas de exploración funcional en los laboratorios de prácticas de fisiología

El escenario físico utilizado para estas clases prácticas es el siguiente: camillas separadas por cortinas con mesitas adosadas para equipo instrumental. Bicicletas estáticas para realizar ejercicio físico. Poyatas de laboratorio para las prácticas que las requieran.

Un paso previo imprescindible para la realización de una práctica instrumental es el estudio del protocolo de la misma, accesible a través de Internet. Después de leer el protocolo y ver los vídeos correspondientes, los estudiantes deben conocer perfectamente lo que han de realizar en la práctica. Para verificar el conocimiento del protocolo, cada estudiante deberá llevar a cabo una autoevaluación on-line, requisito imprescindible para la realización de la práctica.

\section{Clases prácticas de exploración funcional con ordenador}

A través de Internet, los estudiantes realizan prácticas simuladas en laboratorios virtuales, seguidas de una autoevaluación. Un ejemplo de este tipo de prácticas puede consultarse en el libro Virtual Exercise Physiology Laboratory (Kolkhorst, 2003).

\section{Clases prácticas de exploración funcional en medio hospitalario}

Algunas exploraciones funcionales se realizan en el hospital, ya que dispone de los equipos instrumentales necesarios. Por otra parte, es también importante que el estudiante verifique cómo se utilizan los conocimientos básicos en la actividad clínica. Los estudiantes asisten de dos en dos a una intervención cardíaca extracorpórea y a un cateterismo y, en grupos más numerosos, a la exploración del ciclo cardíaco y a otras exploraciones funcionales.

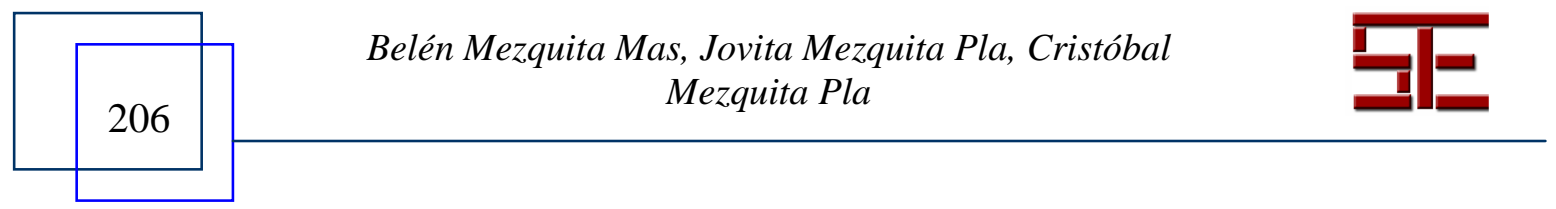




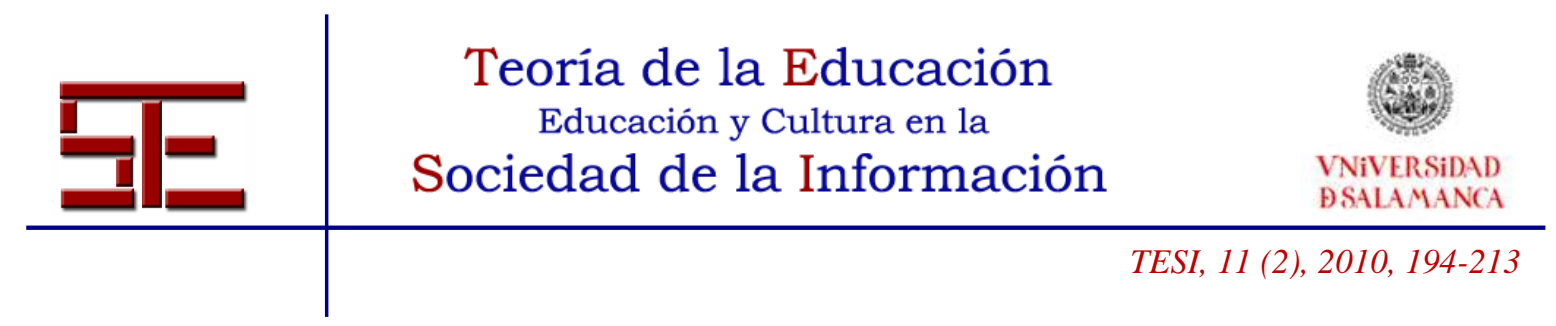

\section{6.- Trabajos bibliográficos, presentaciones multimedia y pósters realizados por los estudiantes}

$\mathrm{Al}$ comienzo de curso, se proponen una serie de relaciones causa-efecto entre variables que únicamente pueden resolverse consultando la bibliografía reciente. Las preguntas se encuentran en el campus virtual y los estudiantes pueden responder a las preguntas previas la consulta bibliográfica accesible desde la misma plataforma. Una vez los alumnos han consultado las bases de datos e identificado el artículo o artículos pertinentes, comunican, a través de la plataforma Moodle, sus respuestas: 1) Contestación a la pregunta formulada (4-5 líneas). 2) Indicación de la idea experimental que ha permitido llegar a las conclusiones formuladas (4-5 líneas). 3) Referencias bibliográficas. Las respuestas son evaluadas y los alumnos seleccionados eligen un grupo como máximo de cinco estudiantes para preparar una presentación multimedia o un póster. Cualquier miembro del grupo puede ser seleccionado aleatoriamente para exponer la presentación oral o el póster (Figura 4). Las presentaciones orales y los pósters deben tener el contenido siguiente: 1) Título. 2) Autores. 3) Resumen que explique la relación entre las variables propuestas. 4) Ilustración de los resultados experimentales. 5) Discusión y 6) Bibliografía.

\section{7.- Evaluaciones}

Tal como se ha comentado, todas las actividades que realizan los alumnos, desde su participación en las clases teóricas y prácticas hasta los trabajos bibliográficos, son objeto de evaluación. Una importancia particular se otorga a la evaluación de las clases prácticas. La evaluación continuada de las actividades que realiza el alumno sustituye a las tradicionales evaluaciones parciales. La distorsión en el funcionamiento normal que provocan las evaluaciones parciales aconseja su sustitución por las pruebas de evaluación continuada. Las evaluaciones realizadas mediante ordenador permiten la utilización de sonidos y de vídeos y la posibilidad de presentar las preguntas de forma secuencial. Otra ventaja importante de las autoevaluaciones es la posibilidad de proporcionar "feedback" y valorar la capacidad autocrítica del alumno en las respuestas abiertas. Por ejemplo, se plantea la definición de una variable. El alumno define la variable. A continuación se proporciona la respuesta correcta y se pregunta: ¿Crees que tu definición ha sido correcta?. Ventajas adicionales son la economía de tiempo en la corrección de respuestas cerradas y la gestión de las calificaciones. El examen en soporte de papel es aún insustituible para las representaciones gráficas, si los estudiantes no disponen de un tablet-PC. Las definiciones de variables, los rangos de valores fisiológicos, las relaciones cualitativas y cuantitativas entre variables independientes y variables función y el establecimiento de secuencias causa-efecto en un conjunto de variables son las cuestiones principalmente exploradas en las evaluaciones.

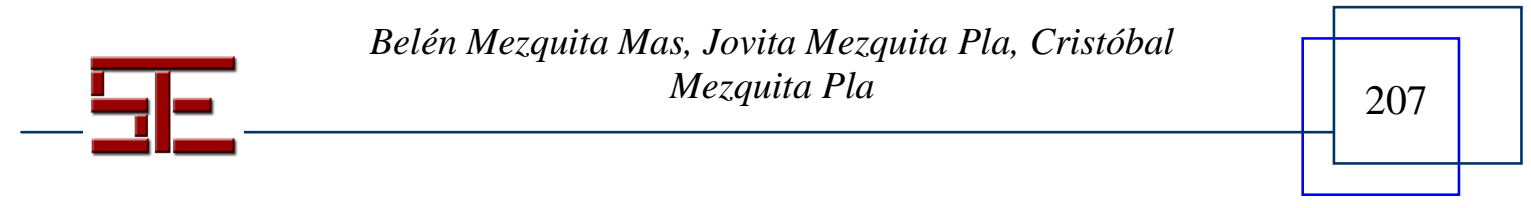




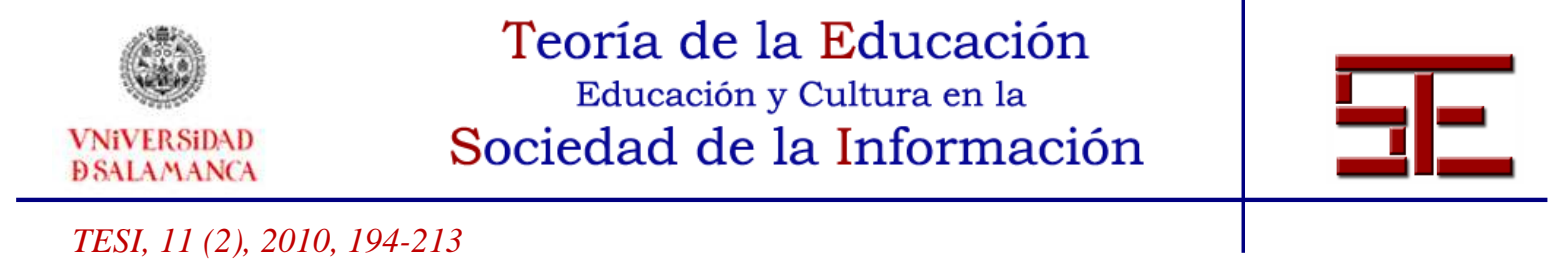

\section{4.- ASIGNATURA "BIOMEDICAL DISCOVERIES"}

Otra iniciativa para mejorar la formación científica de los estudiantes de medicina consiste en aproximarles a las actividades desarrolladas por los científicos. En este sentido propusimos la creación de la asignatura optativa "Biomedical Discoveries", una asignatura semestral que se imparte los viernes durante dos horas. El número máximo de estudiantes matriculados es de 45. Las clases son en inglés, así como el material que utilizamos (libros, artículos de revistas, vídeos y podcasts). Lejos de proponernos enseñar inglés a los estudiantes, nuestra intención es animarles a utilizar el inglés como lengua vehicular de la ciencia.

Nuestro objetivo es aumentar la motivación científica de los estudiantes aproximándolos, por un lado, a los investigadores y, por otro lado, dándoles a conocer los problemas de la medicina global, que únicamente pueden resolverse a través de la ciencia y de las actitudes solidarias. A continuación se indica el contenido de las clases de esta asignatura.

\section{1.- "RX for survival"}

Las clases empiezan con la proyección de un vídeo durante unos 30 minutos, seguido de un breve coloquio libre. Entre los vídeos seleccionados cabe destacar los de la colección "RX for survival", un proyecto de la televisión pública americana PBS que trata de dar a conocer, a través de vídeos documentales, los problemas de salud global.

El siglo XX representó una edad de oro para la medicina global: se descubrieron las vacunas y la forma de curar múltiples enfermedades. La esperanza de vida media de la población aumentó de forma considerable. No obstante, en las últimas décadas este espectacular progreso ha decaído de forma dramática. A pesar de que la esperanza de vida se mantiene alta en los países más desarrollados, en muchos países subdesarrollados la esperanza de vida, de hecho, ha disminuido.

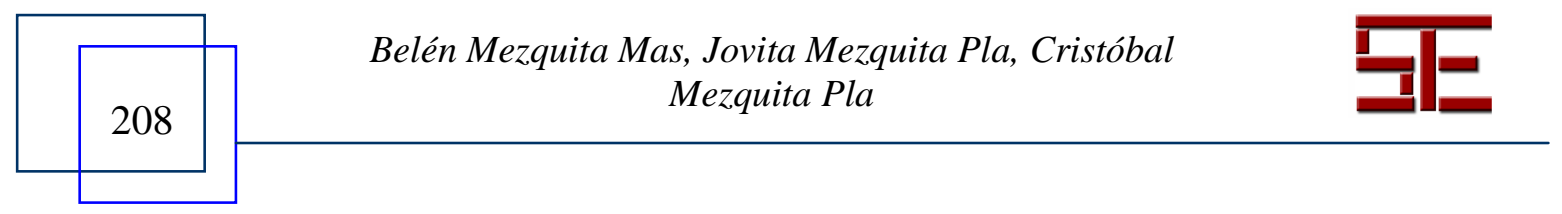



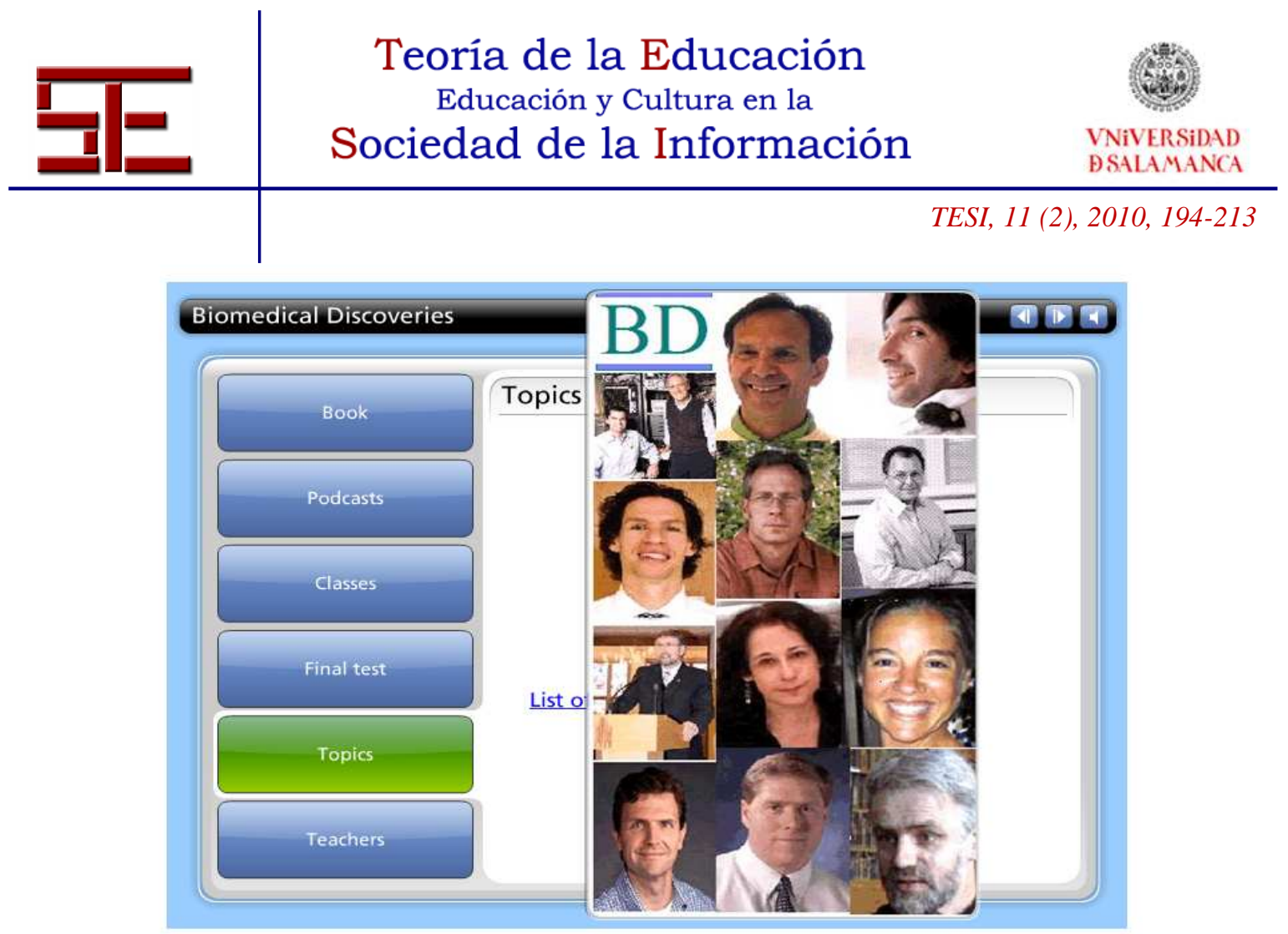

Fig. 5. La asignatura "Biomedical Discoveries" busca una aproximación a los científicos clásicos y actuales.

El progreso hacia una mejor salud global se ha visto obstaculizado por la emergencia de nuevas y devastadoras enfermedades como el SIDA, el SARS, la encefalitis causada por el virus del Nilo, o la aparición de resistencias a los antibióticos y la rápida propagación de enfermedades por la facilidad en el transporte aéreo, que puede convertir una enfermedad local en un problema internacional en cuestión de horas.

El proyecto "RX for survival" pretende dar a conocer estos problemas de salud global pero, sobre todo, insta a pasar a la acción, poniendo como ejemplo la actividad llevada a cabo por multitud de héroes anónimos que, día tras día, luchan contra la enfermedad en distintas partes del mundo.

\section{2.- Microbe Hunters}

Después de la proyección del vídeo, los siguientes 30 minutos los dedicamos a tratar sobre los descubrimientos de los primeros "cazadores de microbios", tomando como pauta el libro Microbe Hunters de Paul de Kruif. Este libro fue escrito el 1926 y desde entonces se ha convertido en un clásico entre los libros de divulgación científica. Microbe Hunters narra los descubrimientos de Leeuwenhoek, que fue el primero en observar la vida microscópica, continúa con Spallanzani, Pasteur, Koch, Metchnikoff...

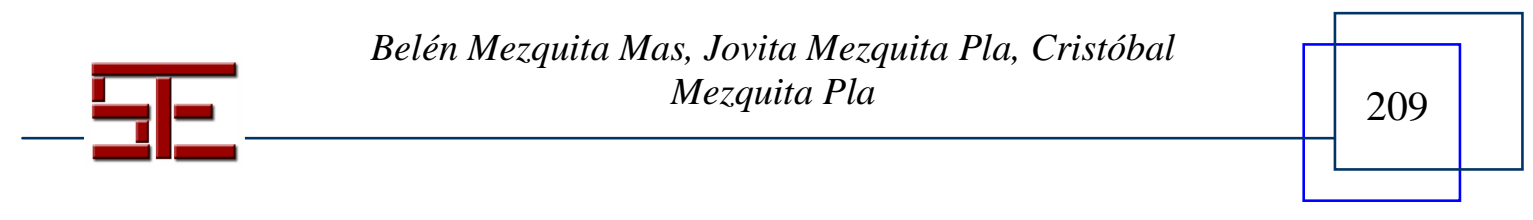




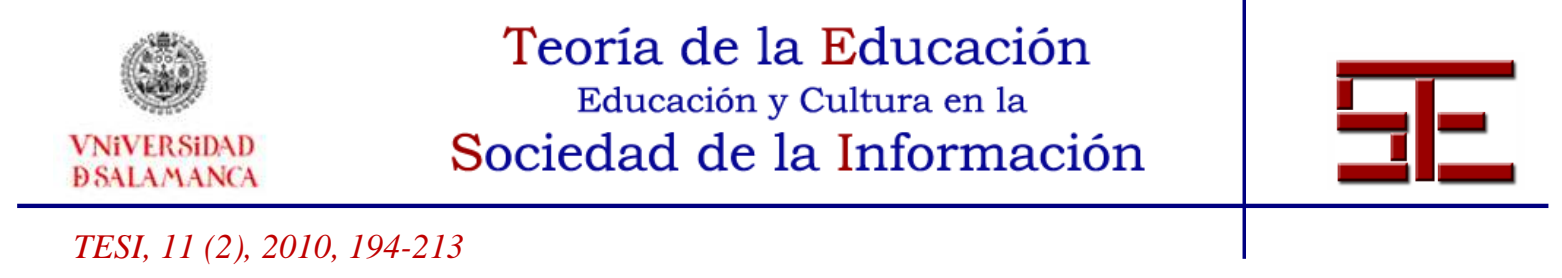

Paul de Kruif supo utilizar un estilo directo que fácilmente transmite al lector el entusiasmo que debieron sentir estos primeros microbiólogos al realizar sus descubrimientos. "How I wish I could take myself back, could bring you back, to that innocent time when men were just beginning to disbelieve in miracles and only starting to find still more miraculous facts. How marvelous it would be to step into that simple Dutchman's [Leeuwenhoek's] shoes, to be inside his brain and body, to feel his excitement (...) at his first peep at those cavorting "wretched beasties".

Cada semana dos estudiantes se encargan de presentar, en inglés, un PowerPoint sobre cada uno de los protagonistas de los diferentes capítulos del libro. Después de una exposición de 15 minutos, se abre un turno de preguntas en inglés, en las que, sucesivamente, los alumnos cuyos nombres aparecen en pantalla de forma aleatoria, formulan preguntas sobre los investigadores. Los autores de la presentación disponen del libro de referencia y elaboran un resumen que se coloca, la semana anterior a la clase, en el campus virtual, a fin de que la audiencia pueda formular preguntas con más facilidad.

\section{3.- What's new?}

En esta sección, el profesor dispone de 15 minutos para comentar brevemente un tema de actualidad. También nos proponemos utilizar esta sección para invitar a otros profesores de la facultad a exponer sus investigaciones a los estudiantes.

\section{4.- Podcasts científicos.}

En la última parte de la clase, un par de alumnos presentan un tema candente de investigación a partir de un podcast de una revista científica. Muchas revistas disponen actualmente de podcasts: entrevistas que pueden ser vistas o escuchadas por Internet. En dichas entrevistas los investigadores exponen sus trabajos de forma divulgativa.

Previamente a la clase, los profesores publicamos los podcasts seleccionados (texto y sonido o videopodcast) en la web de la asignatura y suministramos, además, el formato MP3 para que pueda ser oído reiteradamente por ordenador o en un dispositivo MP3. Paralelamente pueden consultarse los artículos científicos originales sobre los que se basan las entrevistas. Los alumnos encargados de presentar un podcast disponen de 15 minutos para exponer su trabajo y, a continuación, se abre un turno de preguntas para que el resto de estudiantes participe en la discusión sobre el tema.

La asignatura se completa con una sesión práctica en la que se reproducen en el laboratorio los experimentos clásicos de Pasteur y otra sesión en un laboratorio virtual

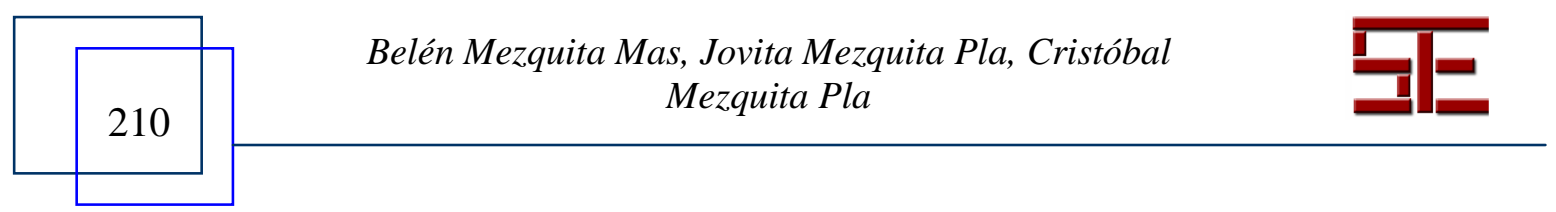




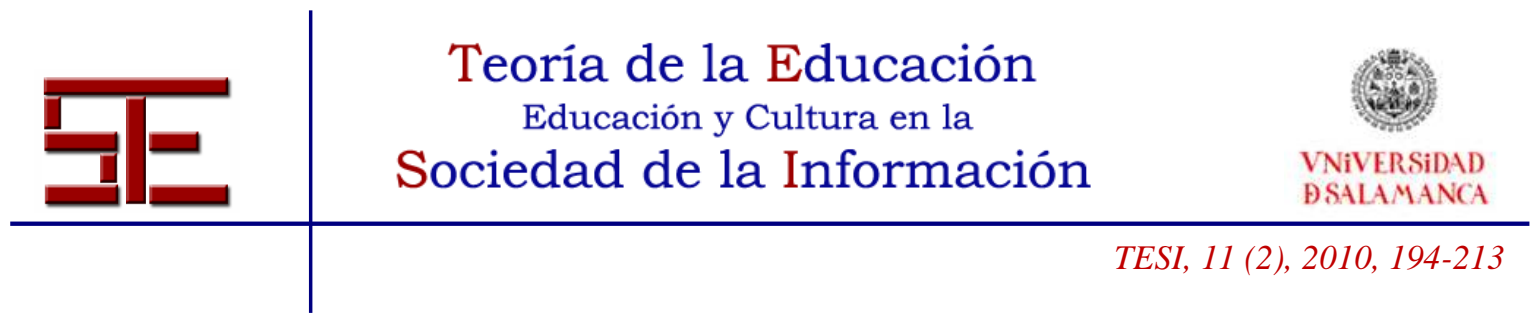

para realizar una identificación de bacterias (Howard Hughes Medical Institute www.hhmi.org/biointeractive).

La participación de los estudiantes en las distintas actividades de la asignatura es objeto de evaluación continuada.

\section{5.- FORMACIÓN DE LOS ESTUDIANTES EN EL LABORATORIO}

Por último, un número limitado de estudiantes reciben formación científica en nuestro laboratorio. Esta posibilidad es particularmente necesaria para estudiantes de la Facultad de Medicina, que desgraciadamente no disponen, en nuestro país, de otras alternativas para formarse en el laboratorio mientras estudian medicina. En el resto del mundo hay un gran número de Facultades de Medicina, más de 300 en EEUU, que desarrollan el doble programa $\mathrm{MD} / \mathrm{PhD}$, que permite una adecuada formación científica de los estudiantes de Medicina. Los estudiantes de otros grados disponen actualmente de posibilidades de formación científica en Biomedicina a través de los programas de Biomedicina o Ciencias Básicas de la Medicina, pero paradójicamente las mismas posibilidades se niegan a los estudiantes de Medicina.

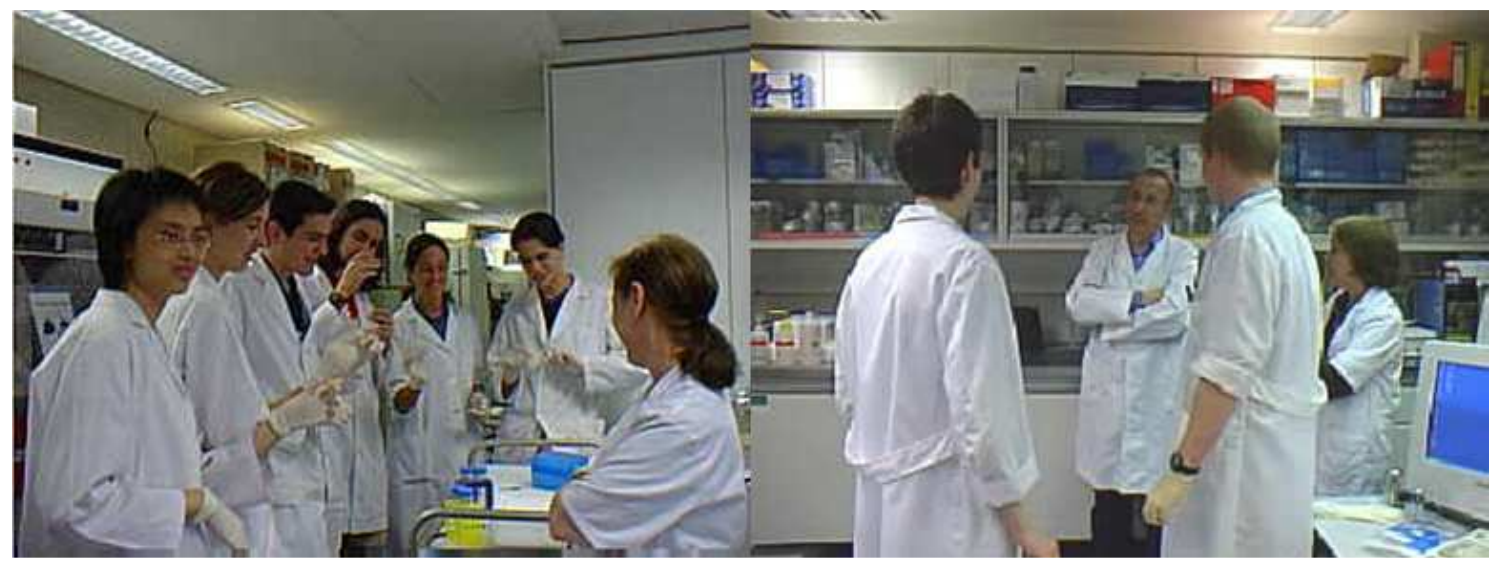

Fig.6. Un número reducido de estudiantes de medicina reciben formación científica en el laboratorio.

Los alumnos que solicitan entrar en nuestro laboratorio y son admitidos siguen primero los seminarios científicos de nuestro grupo de investigación y se les recomienda adicionalmente que sigan los seminarios científicos de la Facultad. Durante el mes de julio, junto a alumnos de universidades extranjeras que lo solicitan, realizan una inmersión en el laboratorio siguiendo y realizando protocolos experimentales. La falta de financiación reiterada que hemos sufrido en los últimos años está asfixiando esta iniciativa.

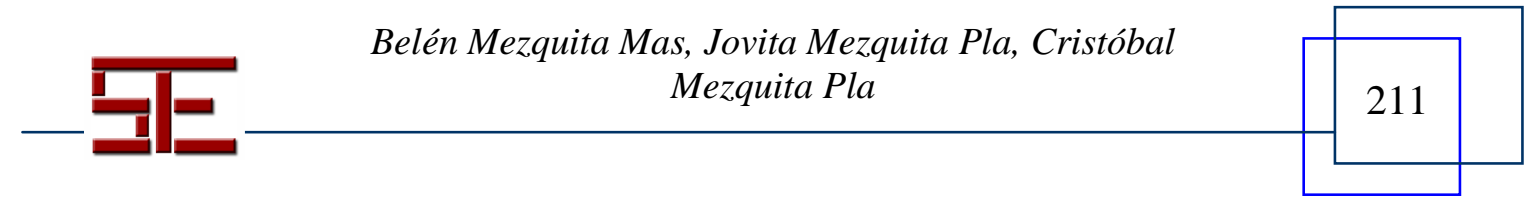




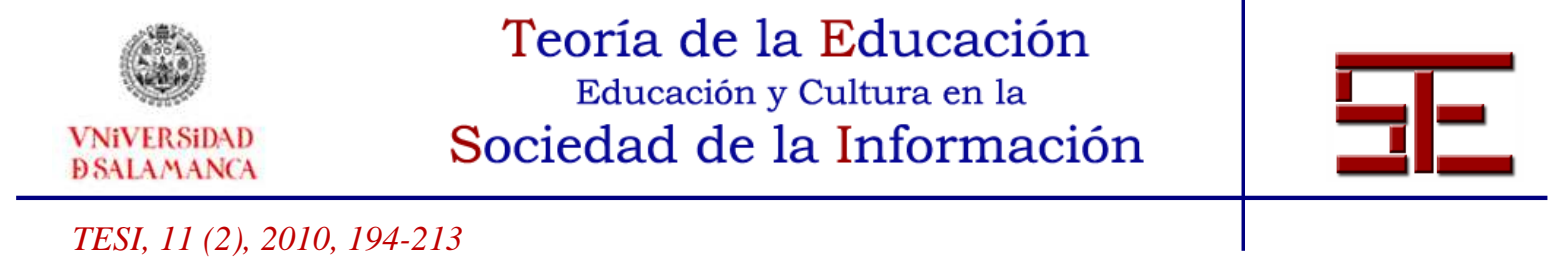

El aprendizaje en el laboratorio es una constante lección de humildad. En el laboratorio se aprende mucho más que saber hacer cosas. Se aprende acerca de la complejidad que supone dar respuesta a las preguntas planteadas y se aprende también a valorar la importancia de los detalles más insignificantes. Cualquier variable puede introducir error. El método y el rigor experimental son fundamentales. Los resultados han de ser reproducibles y han de obtenerse aplicando más de un método. El objetivo de la enseñanza en el laboratorio es, para el profesor, demostrar al estudiante cómo se obtiene el conocimiento y, para el estudiante, demostrarse a sí mismo que es capaz de obtener dicho conocimiento. También es fundamental plantear bien las preguntas y tener muy claros los objetivos.

Los estudiantes escriben en su libro de protocolos las diferentes partes del trabajo experimental: introducción, material y métodos, resultados y discusión (Mezquita, 2000). La primera vez que el estudiante aborda un objetivo experimental sigue el protocolo experimental y comprueba que el profesor obtiene el resultado deseado. Progresivamente, el alumno, tutelado por el profesor, se familiariza en el manejo y la utilización de los procedimientos experimentales hasta ser capaz de realizar el experimento de forma independiente. Con los resultados obtenidos, el estudiante, con la ayuda del profesor, redacta un esbozo de publicación que se discute en los seminarios del grupo.

\section{6.- CONCLUSIONES}

De todo lo anteriormente expuesto cabe destacar, como conclusión, que el avance experimentado en las nuevas tecnologías de la comunicación permite tutelar, de manera cada vez más individualizada, la formación intelectual de nuestros estudiantes, haciendo accesible a un gran número lo que en otro tiempo estuvo reservado a un número muy reducido de discípulos.

Nuestra experiencia es gratificante por la respuesta de los estudiantes, pero es posible que no sea sostenible a largo plazo por falta de un adecuado apoyo institucional. Cada vez resulta más difícil competir en la obtención de recursos con los grupos que se dedican únicamente a la investigación. El crecimiento y estabilidad de los equipos docentes no puede depender únicamente, como hasta ahora, de la relación carga docente / fuerza docente (número de horas de docencia/número de miembros del equipo). Más bien debería estar basada en la siguiente relación: Evaluación del proyecto docente + Evaluación del proyecto de investigación / Número de miembros del equipo. Si no se garantiza el equilibrio y la integración entre la creación científica y la actividad educativa, se extinguirá con el tiempo la idea misma de Universidad.

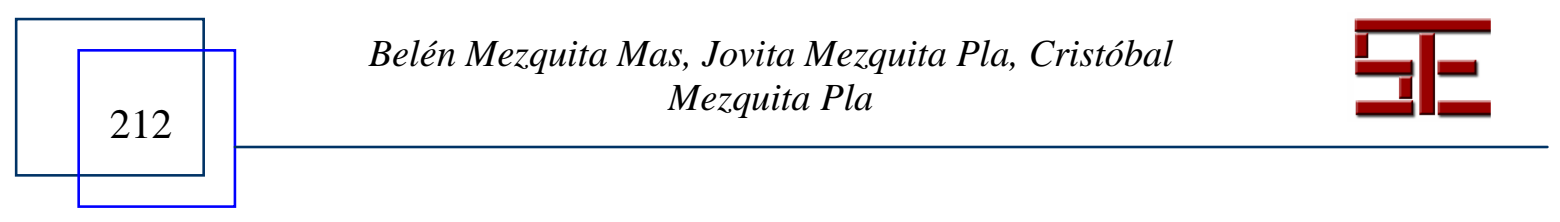




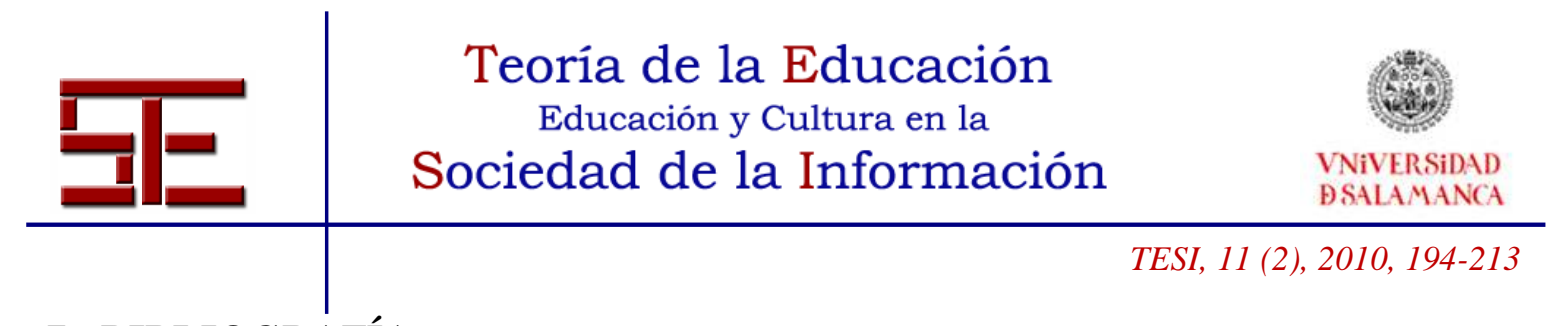

\section{7.- BIBLIOGRAFÍA}

Cooke, M., Irby, D., Sullivan, W \& Ludmerer, K. (2006). American Medical Education 100 Years after the Flexner Report. N Engl J Med, 355, 1339-1344.

Kohn, L., Corrigan, J \& Donaldson, M. (1999). To err is human: building a safer health system. Washington, D.C, National Academy Press.

Kolkhorst, F. (2003). Virtual Exercise Physiology Laboratory. Philadelphia, Lippincott \& Wilkins.

Mezquita, B., Mezquita, J., Petit, M., Jornet, A \& Mezquita, C. (2009). Howto improve the formal analytic reasoning and scientific motivation in the intellectual training of medical students. Simposio Internacional CIDUI 2009.

Mezquita, C \& Mezquita, B. (2010). Fisiologia dels Sistemes Circulatori, Respiratori $i$ Renal ( 6 a edición). Barcelona, Publicacions i Edicions de la UB.

Mezquita, J. (2010). Fisiologia de la Reproducció $i$ Desenvolupament Humà (4a edición). Barcelona, Publicacions i Edicions de la UB.

- (2000) Métodos de Genética Molecular. Barcelona, Jordi Blassi, editor.

Patel, V., Arocha, J \& Zhang, J. (2004). Thinking and reasoning in Medicine, en KEITH HOLYOAK (eds) Cambridge Handbook of Thinking and Reasoning. Cambridge, Cambridge University Press.

Para citar el presente artículo puede utilizar la siguiente referencia:

Mezquita Más, B., Mezquita Pla, J. y Mezquita Pla, C. (2010): Cómo mejorar el razonamiento causal y la motivación científica en la educación intelectual de los estudiantes de medicina. Utilización de nuevas tecnologías en la metodología docente, en Juanes Méndez, J. A. (Coord.) Avances tecnológicos digitales en metodologías de innovación docente en el campo de las Ciencias de la Salud en España. Revista Teoría de la Educación: Educación y Cultura en la Sociedad de la Información. Vol. 11, n 2. Universidad de Salamanca, pp. 194-213 [Fecha de consulta: dd/mm/aaaa].

http://campus.usal.es/ revistas_trabajo/index.php/revistatesi/article/view/7077/7110

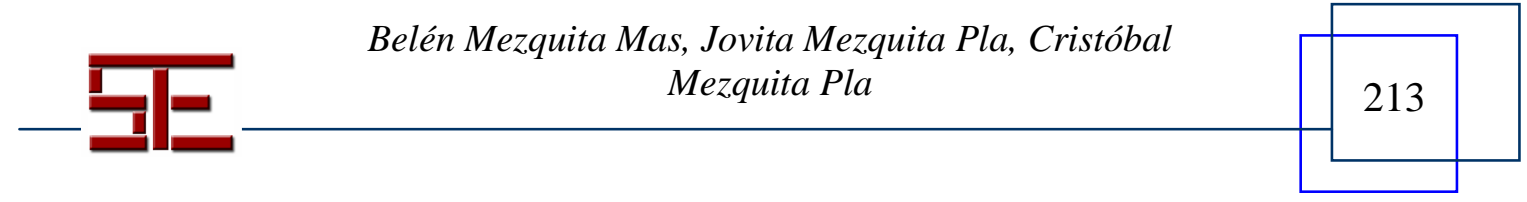

